\title{
From Fungi to Fairies: Exploring, Theorizing, and Documenting Learning Through Visual Arts
}

\author{
Raewyn Penman and Rachael Maiden
}

Raewyn Penman, MBA, is currently an education service manager for Kidsfirst Kindergartens, providers of education for children from birth to 6 years old throughout the South Island of New Zealand. Raewyn brings her extensive experience as a teacher in both kindergartens and early childhood centres, as a professional development facilitator, a preservice lecturer, and an owner of early childhood centres to her work with leaders and teachers in the early childhood sector. She is passionate about supporting teachers to critically reflect on their practice, extend their theoretical and research knowledge, and become innovative in their practice. Email: Raewyn.Penman@kidsfirst.org.nz

Rachael Maiden (Diploma Teaching ECE) has been involved in early childhood education in New Zealand for the past 20 years, first as a teacher and more recently as director of the educational consultancy company Wildfeathers. She has a passion for promoting visual arts as an authentic way to connect with children and to support them to express themselves, their knowledge, and their discoveries. Rachael's teaching practices are underpinned by a strong pedagogy of listening and they inspire teachers, children, and their parents to become fully engaged in the early childhood program.

The authors discuss the three-year journey of teachers, children, and families as they explored a natural phenomenon and documented learning through the medium of art. Teachers identified strategies that supported and encouraged children to observe, research, and document their learning and ideas in two and three dimensions using a wide variety of media. Learning was made visible to parents and families through visual arts capturing their interest and involvement. Using Deleuze and Guattari's philosophy of thinking to interpret the experiences provides understanding of how flexible teaching strategies can support complex learning over time.

Keywords: visual arts; complexity; Deleuze

In 2011, one of the side effects of the earthquakes in Christchurch, New Zealand, was liquefaction, which, long after the cleanup, facilitated the growth of many varieties of mushrooms not previously seen in the city. This natural phenomenon, for some early childhood services, was a cause for concern, and great lengths were gone to so that the mushrooms were eliminated from the outdoor play areas before children went into the area in case they were harmed. One kindergarten catering for children from 2 to 5 years of age saw the potential for the mushrooms to become a rich source of learning for the children, teachers, parents, and families involved. This kindergarten had recently begun developing their program and the teaching strategies used, focusing on increasing the child-led program, enabling children to make authentic choices about their learning, and growing the pedagogy of listening. The teaching team wanted the children to gain the skills, knowledge, and learning dispositions that would enable them to maximize their creativity and use visual arts as a way to voice their ideas and thoughts and to document and assess their own learning.

\section{Visual Arts as a Communication Tool}

Visual arts are recognized as one of the many languages or ways of communicating used by young children. This is apparent in the Reggio Emilia pedagogy, which has inspired some New Zealand early childhood services. Reggio Emilia schools use documentation as an integral part of the everyday teaching and learning process, where both children and teachers are learning and using documentation to record and develop ideas, thoughts, and observations. This documentation is usually in the form of visual arts and often develops over time.

Pohio (2009), Stott (2011), and Terreni (2010) all highlight the disconnect for many New Zealand early childhood teachers between their sociocultural-based teaching practices used in most areas of the curriculum and a developmental, hands-off 
approach used in teaching visual arts. This disconnect leads to teachers missing opportunities to scaffold learning and coconstruct knowledge. Terreni (2010), a leader in research in visual arts in early childhood in New Zealand, notes that

recognising that visual art provides children with important tools for thinking and learning, and that it is important for teachers to be actively involved in children's visual art experiences is, I believe, fundamental to a successful early childhood visual art programme that recognises the importance of socially and culturally mediated learning. (p. 7)

With the shift from developmental to sociocultural theories in the early years, there has been a growing recognition of the part that visual arts can play in providing children with a vehicle to communicate their ideas, thinking, feelings, understanding, and opinions. Brooks (2009) suggests that using a Vygotskian sociocultural lens to examine the processes involved in drawing is more useful than the Piagetian or developmental lens previously used. With the later lens, children's drawings were seen as a way of determining the child's cognitive level, whereas using a sociocultural perspective, teachers can "begin to better understand how the visualisation of ideas and concepts through drawing can support young children's scientific ideas and higher mental processes" (Brooks, 2009, p. 323). Focusing on drawing as a language and a mediation tool, Brooks (2009) expanded on Vygotsky's theory that showed how verbal thought was the intersection of thought and speech, and produced the diagram seen in Figure 1.

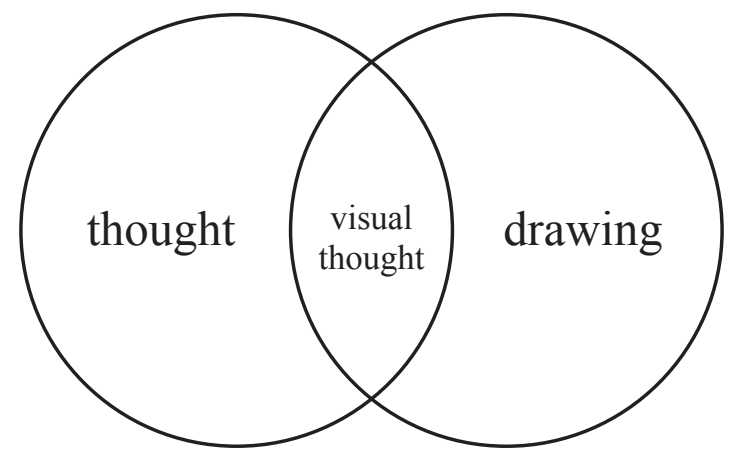

Figure 1: Visual thought. Source: Brooks, 2002, as cited in Brooks, 2009, p. 326.

According to Brooks (2009), "when we study the whole - drawing, thinking and meaning within the sociocultural and historical contexts of the production of drawing - then we are able to see how children use drawing as a meaning-making tool” (p. 326). The perspective of New Zealand's Te Whāriki curriculum (New Zealand Ministry of Education, 1996)

is that children will participate in the symbol systems and technologies of the arts: for personal, social, and cultural purposes; for becoming confident and competent in culturally valued enterprises; for expressing emotion; for making connections across place and time; for contributing their own abilities and viewpoints to the community; for communicating with others (including appreciating the ways in which the available cultures communicate and represent); and for making sense of their worlds. (New Zealand Ministry of Education, 2009, p. 4)

From this perspective, visual arts can be seen as a holistic vehicle that can be used to promote positive learning outcomes for children across the early childhood program. Te Whāriki has the development of working theories as one of its two learning outcomes. Although understanding of working theories is still growing, there is some agreement that they are developed through observing, discussing, representing, revising, and refining understandings as the child is involved in new experiences and develops new thinking (Hargraves, 2014; Hedges \& Jones, 2012). MacDonald (2013) found that drawing was a powerful tool for children to use as they increased their understanding of mathematical concepts. She found that it is "not just a procedure by which children record their knowledge about a concept, it is also a process through which understandings can be constructed, re-considered and applied in new ways" (p. 72). Brooks (2009) also noted that drawing allows "ideas to be re-contextualised, revisited and revised" (p. 339). This capacity of visual arts enables children, through 
representing their thinking, to share their ideas with their peers and teachers, coconstruct knowledge, participate in inquiry learning, work at a metacognitive level, and develop increasingly complex working theories.

\section{A Framework for Interpreting Learning Experiences}

Since the mid 1990s, sociocultural theory, particularly the work of Bronfenbrenner and Vygotsky, has informed our thinking, our curriculum, and our interpretation of the learning experiences children are involved in. Within this there has still been a tendency to think of skills, abilities, and knowledge to be progressing in a linear way, not necessarily the same for all children, but still with one thing building on another. When reflecting on the learning experiences happening in the journey described in this article, we realized that the interpretation was more complex, more flexible, than can be explained in a linear way. Over the same period, there has been increasing use of the philosophy of Gilles Deleuze and Félix Guattari in interpretation of research findings in early childhood education (Duncan \& Eaton, 2013; Osgood, Albon, Allen, \& Hollingworth, 2013). While the work of Deleuze and Guattari on the philosophy of thought has many complex concepts, their concepts of arborescent and rhizomatic thinking, plateaus, and lines of flight challenge linear and outcomes-based thinking and provide a possible framework for interpreting learning experiences. Sellers (2013) draws on these concepts to reenvision the discourses on early childhood education, children, and the curriculum in New Zealand.

\section{Arborescent and Rhizomatic Thinking, Plateaus, and Lines of Flight}

Deleuze and Guattari use the term arborescent thinking to describe the conventional linearity of thought. Sellers (2013) explains that "the arborescent thinking of the tree of knowledge utilizes concepts of branches and roots through which we 'receive' knowledge from the past, develops it within the present and passes its fruits on to future generations" (p. 11). This thinking is characterized by containment, a beginning, a middle, and an end, and repetition of the same or similar when the tree is "reproduced." In contrast, rhizomatic thinking is complex; it moves both horizontally and vertically and can become very intense, tangled, and layered on top of / beside itself. "To imagine an experience as rhizome," Amorim and Ryan (2005) write, "is to accept that the experience itself can grow from its extremities or limits" (p. 583). Rhizome is a botanical term used to identify the root and growth system of such plants as root ginger or iris. Coming from New Zealand, we chose to think of the rhizome in terms of the fern, one of our national symbols, where the multidirectional and multilayered growth of the roots represents the complexity of learning and the sprouting and unfurling of the fern fronds is often used to symbolize the growth of the infant and child in our indigenous Māori culture. Rhizomes are in-between, never at the beginning or the end, and if they are broken or interrupted will grow again in the same or different direction. In the context of thinking and experiences, the rhizome opens up an infinite range of interconnected possibilities leading in many and varied directions.

Deleuze and Guattari (1987, p. 22, as cited in Sellers, 2013) "consider a plateau as a "continuous, self-vibrating region of intensities' constituted so as not to develop any external end or final climax" (Sellers, 2013, p. 13). A plateau could be considered an area of intensity that forms and reforms/changes in response to internal and external influences in an unpredictable manner. Rhizomes become plateaus become rhizomes become "always in the middle, amidst everything, generating and generated by circles of convergence" (Sellers, 2013, p. 13). Lines of flight can be thought of as the creative explosion: new variation from one plateau that moves the thinking or activity into another space of existing intensity or new intensity or a plateau previously visited. Revisiting a plateau can open up possibilities not thought of previously. With our naïve, unfolding understanding of Deleuze and Guattari's work, we think that these concepts may provide a good fit when interpreting the learning experiences of a multiplicity of participants over time, as we attempt later in this article.

\section{Fungi to Fairies: A Narrative}

February 22, 2011. A major earthquake hit the city and our kindergarten had a lot of liquefaction that just poured through the garden, covering the playground. Little did we know this liquefaction was going to have an influence on the learning of 
our program for the next three years. Not long after the liquefaction was all cleaned up and our garden was beautiful again, mushrooms began to pop up. They were massive, and they were everywhere. Many varieties not seen before appeared, from big fleshy ones to the beautiful red ones with white spots. They could have been poisonous - in fact, some of them were. Teachers had a choice. They could remove them for health and safety reasons; however, as a team they saw that there was potentially a huge amount of learning here, and, after discussion, felt that there was too much potential, and they couldn't ignore it. So, they started learning about mushrooms.

For the children, during this first season, safety was the key learning-how to keep themselves safe, how to protect each other, and how to care for the mushrooms because they are living things. The children understood the boundaries. They knew what was expected of them, and they responded accordingly. They used gloves when handling the mushrooms. There were plastic bags for the mushrooms to go in, so it was safe to carry them through the play area. Initially we spent time observing the mushrooms. We observed them in the garden, and then we brought them into the kindergarten and we observed them. From the early days, children were given pens and pencils and paintbrushes to record what they could see and begin to document it. Children and teachers researched, drew pictures, used the Internet, used books, used our shared knowledge around mushrooms to make discoveries about what they were, and learnt the language of fungi-toadstools, fungus, spores, and caps - so that it became part of the language of our kindergarten.

Right from the early days, children were using visual art as a way to express their knowledge, but also to keep themselves safe. Sophie had gone mushroom hunting with her mother, found some at home, and brought them in to the kindergarten. You can clearly see from her picture (Figure 2) that she is telling us, do not eat these mushrooms. There's a cross, and spots that represent the mushrooms. Sophie asked the teacher, "Can you please write at the bottom, please do not eat?" When asked why she wanted that written she responded, "Oh, because adults might not be able to read the pictures."

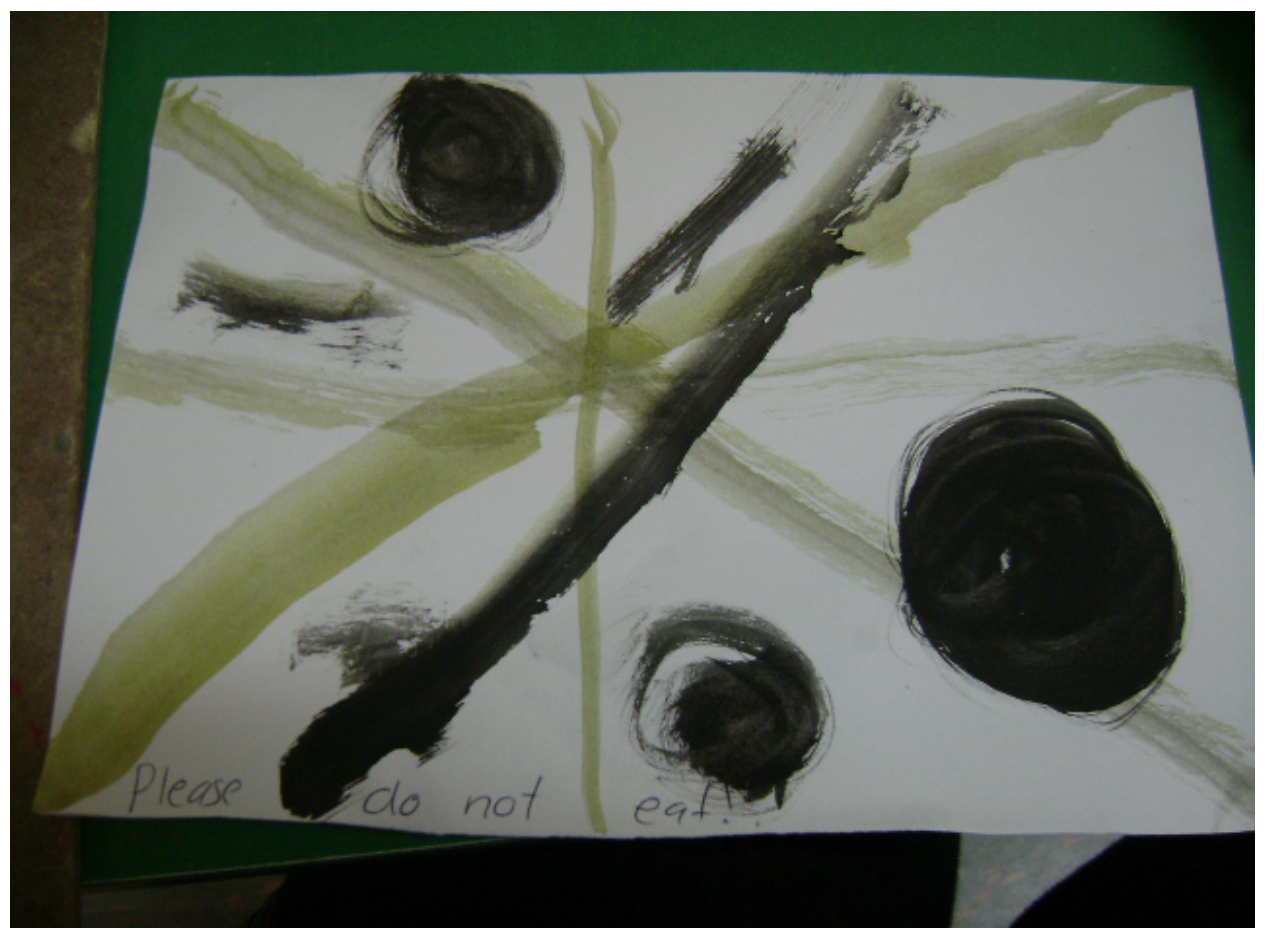

Figure 2. Sophie's sign to keep children safe, with words added so adults understand, too.

The importance of having conversations became apparent very quickly. Teachers discovered that children were producing amazing pieces of work. But unless they worked alongside the children and had conversations, a lot of the learning was missed, and a lot of understanding was being missed. In Figure 3, Connor has drawn a gorgeous mushroom. Initially, when 
the teacher saw this, she figured it was the red mushrooms, with the caps and the spots. When the teacher had a conversation with him, he explained that he'd been learning about the spores and how they drop off the mushroom. Those spots were actually the spores. The teacher would have missed that learning if she hadn't had that conversation with him. She would have missed understanding that he actually knew a lot more than she did. Teachers needed to have those conversations, and they needed to not rush the conversations.

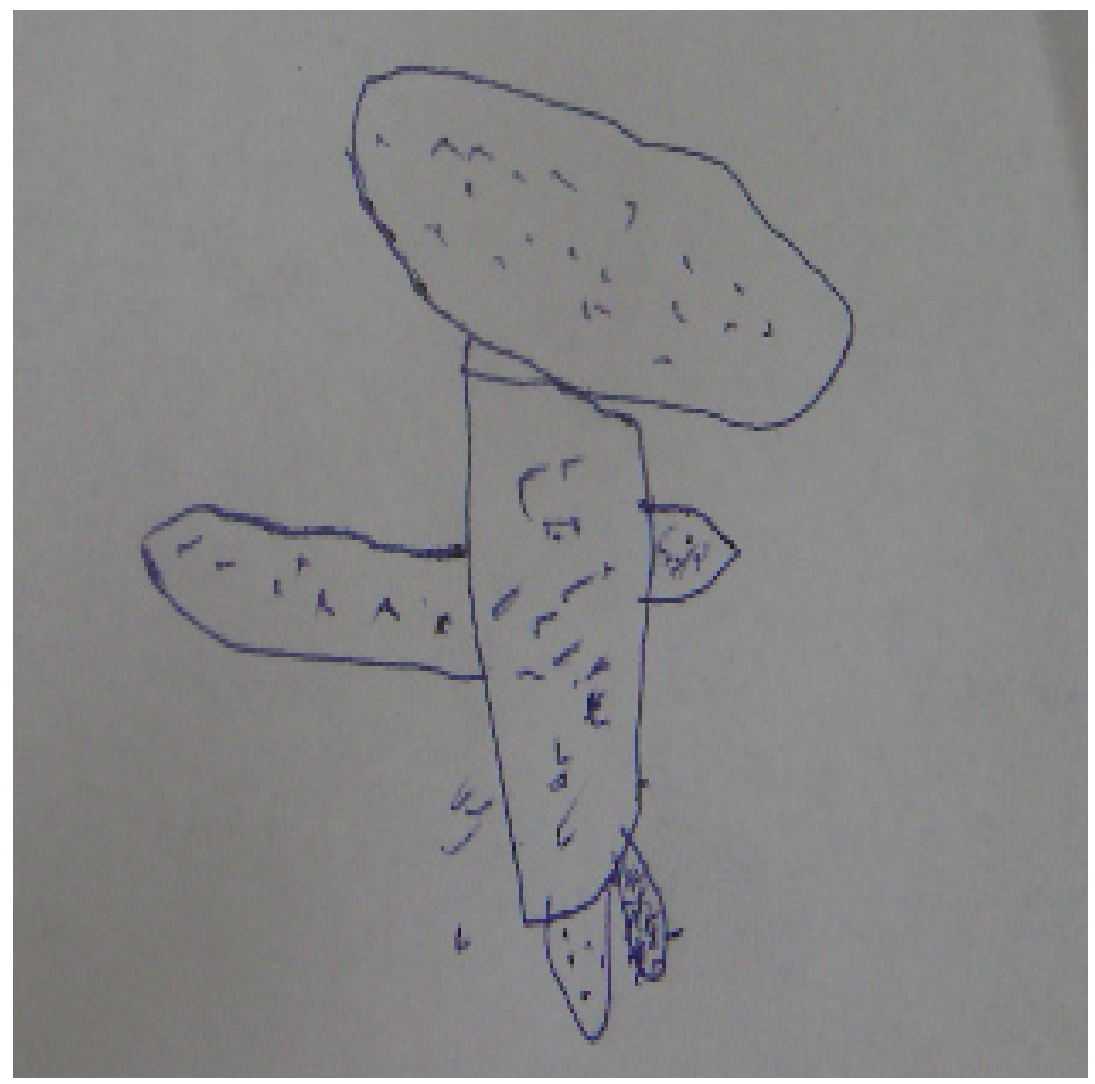

Figure 3. Connor's mushroom, showing the spores, some of which are falling off.

After talking about fungi and things that grow, children wanted to grow their own mushrooms. After being read The Terrible Wild Grey Hairy Thing by Jean Chapman (Chapman \& Kitanov, 1986), the children decided to do an experiment that they called the stink tank. They brought food in, put it in a science cabinet, and documented what happened. Each day photographs were taken, which were seen as another extension of visual art, because some children used that method as their way of capturing their images. Other children drew the mould and the mushrooms; they looked at the shape of the mould at the different colours and they smelt it. The teachers used a narrative assessment tool called learning stories to assess what learning was happening and the direction of the children's interest. These stories were displayed so that parents and families could see what was happening at the kindergarten. The families needed to know why there was a tank of festering food in the kindergarten. The stories explained it to them and got them involved, really capturing their interest. 


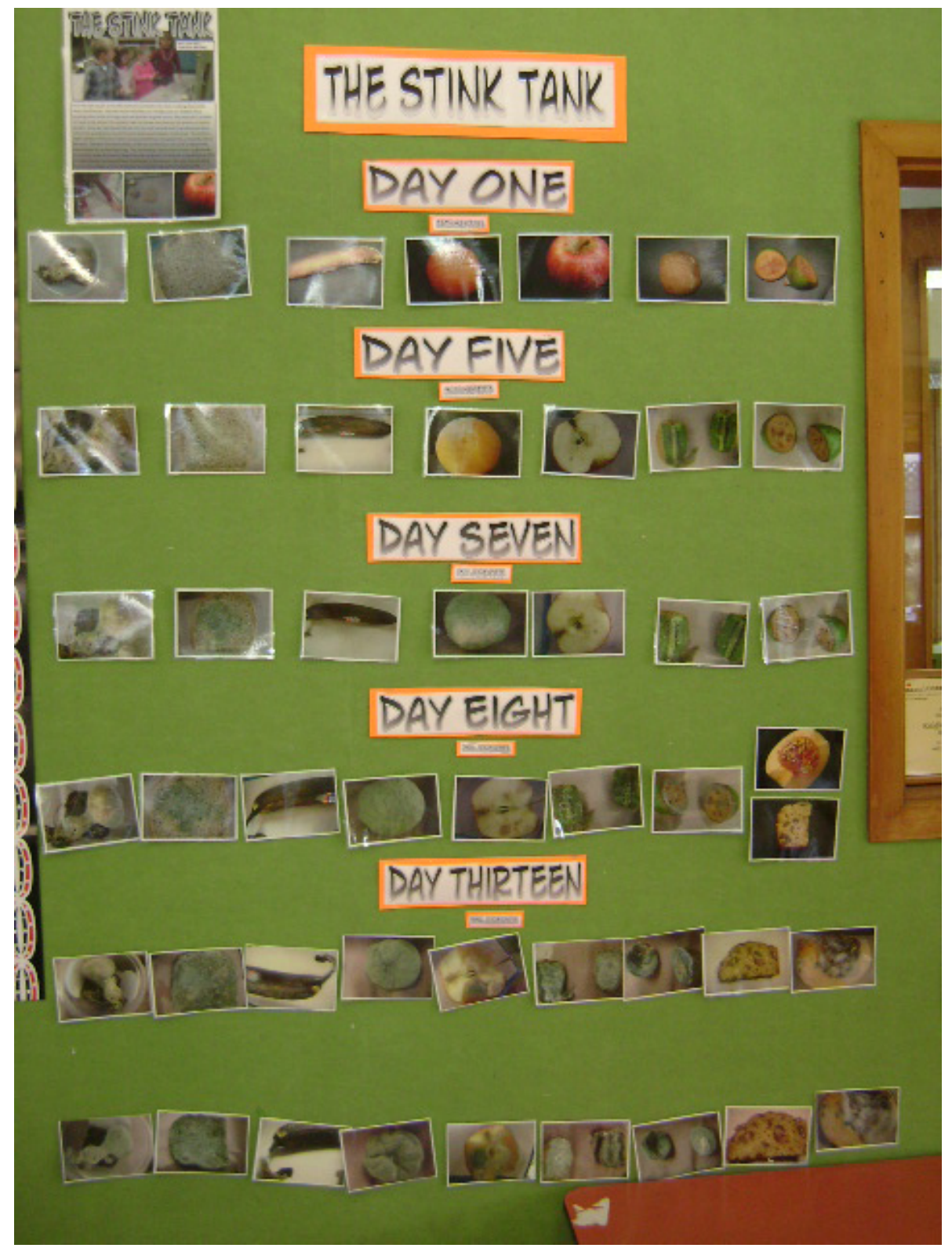

Figure 4. Display of the photos taken by children to record the progressing decay.

Displaying the documentation (Figure 4) was vital for the children, teachers, and families to revisit the learning, to discuss what others knew and how this compared to their knowledge. As you can see in Figure 5, children's language is included in the documentation so that parents could "hear" what the children knew. On a lot of the artwork you can see that teachers have a conversation with the children, capture it, and type it up, displaying it next to the child's picture. That's so that when families come in, they have a starting point. They can have that conversation with children around what the children know. It gives them an understanding about what the picture is about. 


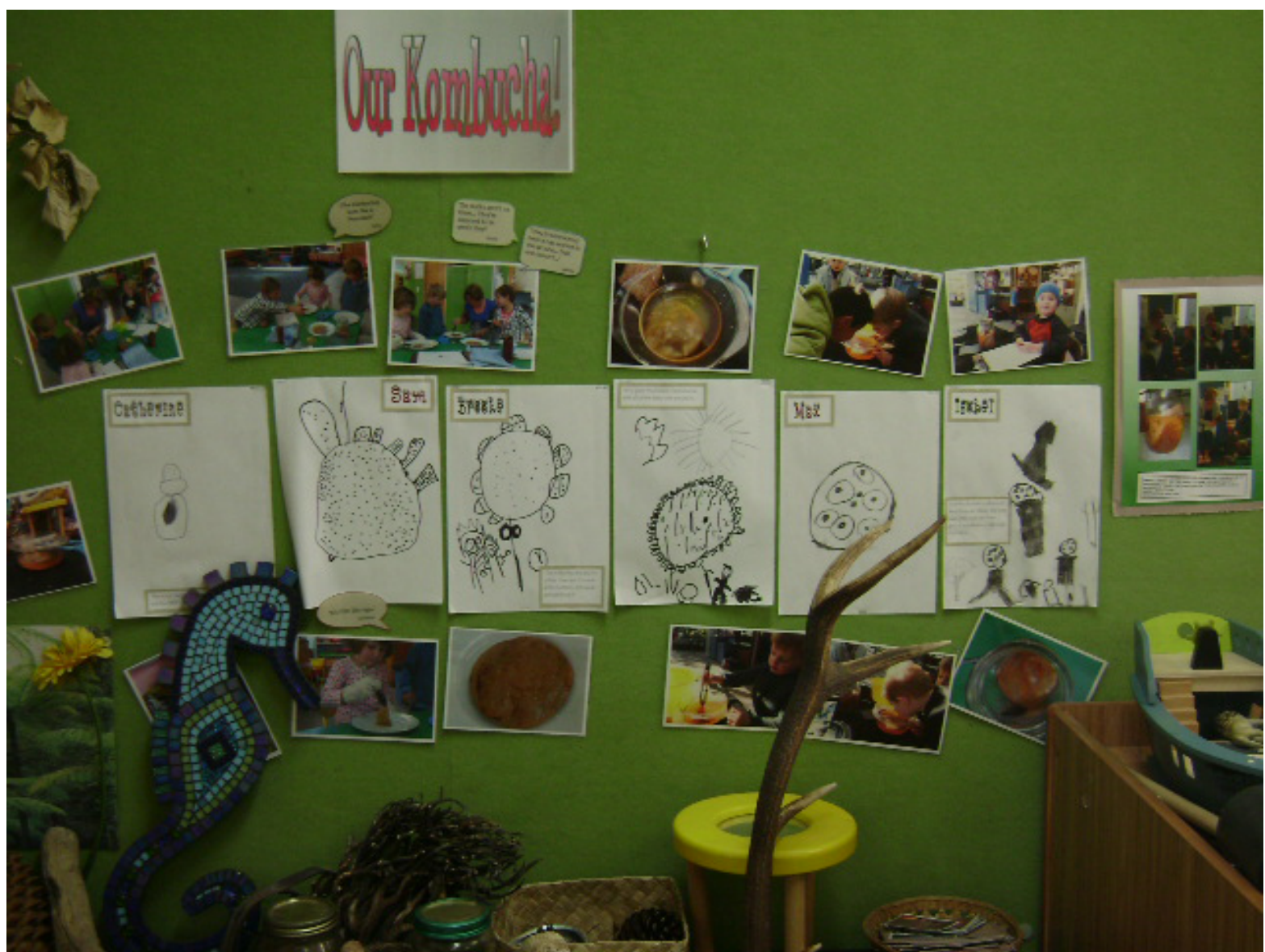

Figure 5. Teachers recorded the conversations and added the children's comments to their pictures if they wanted this.

\section{The Second Season: An Opportunity Missed}

The next year rolled around, and the mushrooms were back. Some of the teaching team had changed, and consequently the way the program was implemented changed. Teachers and children revisited the learning that had happened, using the displays and documentation that had been kept from last season. But the complexity of learning wasn't there. It didn't occur to the same level, and the desire from the teachers to follow this interest was not there. Maybe it was fear of doing what had already been done? The head teacher reflected that the failure to build on the previous learning on this occasion showed the importance of teachers working alongside the children, having conversations, and providing them with the materials.

\section{They're Back!}

When the mushrooms turned up for the third season, the kindergarten had undergone another team transformation, and the new team was very keen to follow this interest. Again, children explored their understanding alongside motivated, excited teachers who used the prior documentation as a starting point. Many children already had a base knowledge, a historical knowledge. The teaching team became experienced at questioning and listening to children when using visual art to document. This meant more complexity was appearing in the children's art. The importance of taking the time to sit 
and listen, without rushing, and to carefully observe objects, and to do so repeatedly, became very apparent. Some children may come in and sit at a table and draw 20 mushrooms. They do that for an hour and then they get up and leave. Other children will come in one day and do a mushroom, and then the next day do a mushroom, and the next day. They will end up completing 20 mushrooms. They have done it their way. What teachers do is set up a new environment that supports children to create in their own way. An environment where children can make choices because there is a program that allows that flexibility.

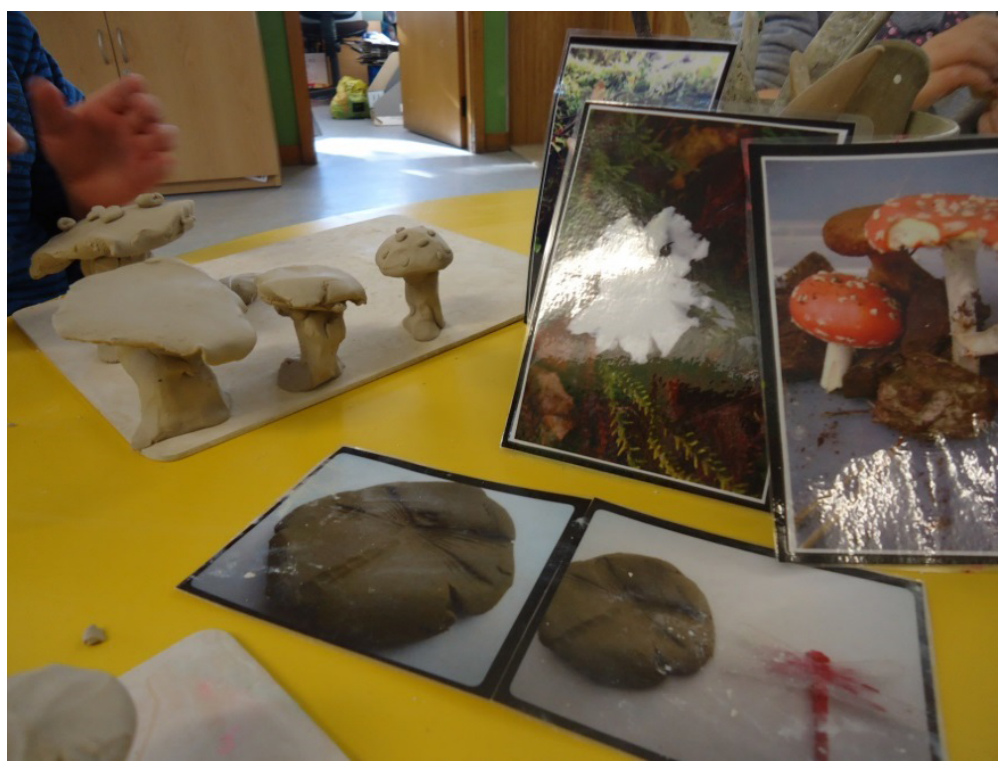

Figure 6. Complexity shown through the medium of clay.

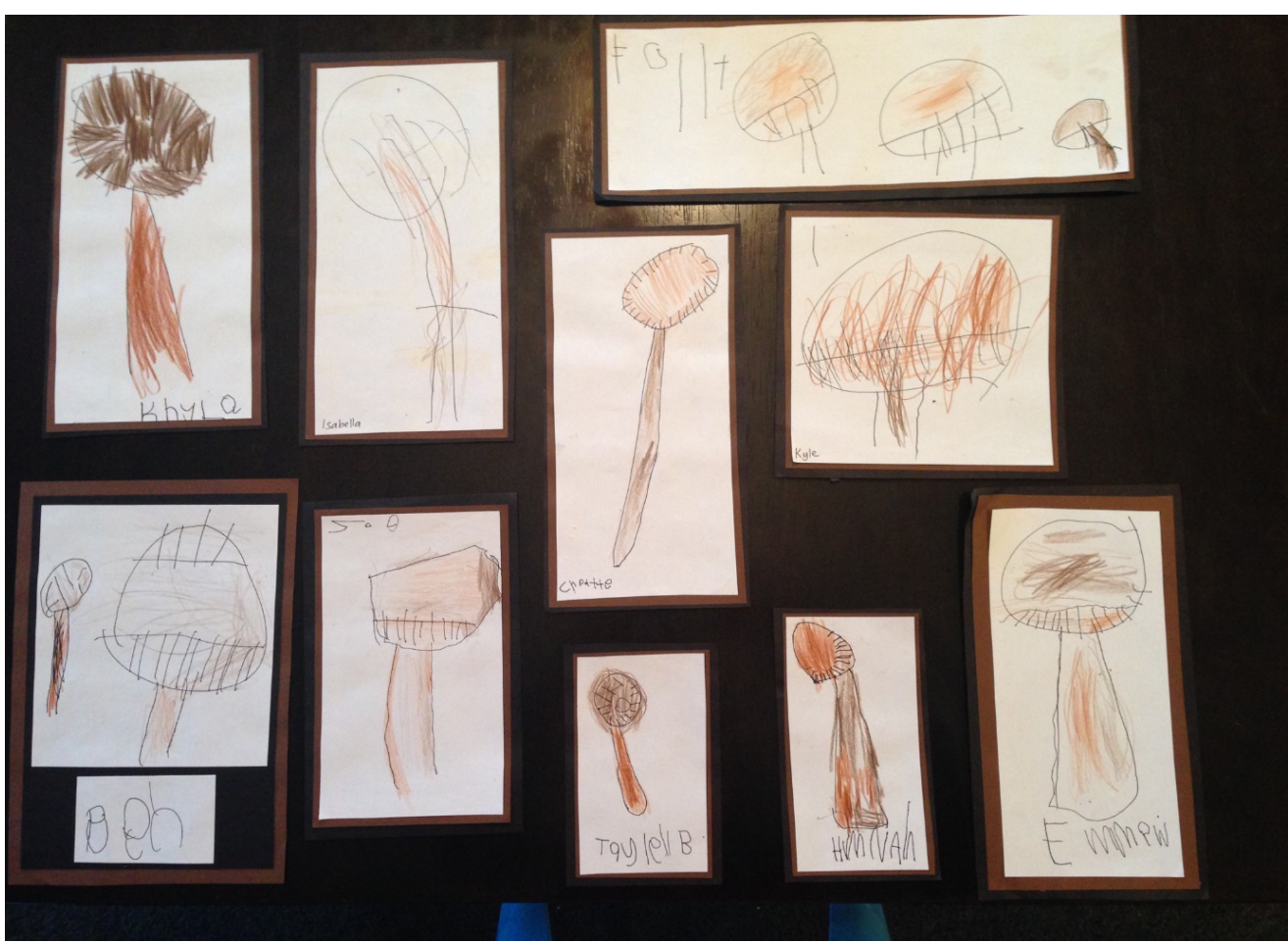

Figure 7. Children's drawings are increasing in complexity and perspective. 
You can see in Figures 6 and 7 the complexity in the artwork developing, more so than in the first year. Teachers became more expert at talking about three-dimensionality. How do you make things stand out? Where do you place that line? Also, children had become more skilled at observing the objects. Their artwork began to show different perspectives. In the series of pictures in Figure 7, Emma's drawing (bottom right) shows three-dimensional skills evolving. Taylor's (bottom middle) is an aerial view. Humnah (bottom, second from right) could see there were gills, but wanted to know "where do I place them?" So children were becoming talented at making observational decisions. Teachers offered lots of materials to support the children's interest throughout the learning environment: If you want to make a mushroom in the sandpit, the resources are there. If you want to use clay, paints, pens, and pencils, they are all readily available. It meant that children could use the way they were most comfortable with to make meaning of their ideas, thoughts, and learning. The teachers had become more experienced at reading what children were wanting and ensuring the program was much more available for the children. To do this, they had all equipment and resources available to the children all the time. As part of the observation process, the teachers had learnt to look at things from different angles, challenging themselves as teachers.

\section{Changes in Pedagogy}

By the end of the third mushroom season, teachers had learnt that preparation of the environment is vital. Preparing the environment allows children freedom to explore, and the tools are there to support this exploration. Documenting is also important because it makes revisiting possible. By revisiting this interest, teachers discovered that a historical community knowledge had developed that children could build on alongside the learning of their peers and of their older siblings in the family. This was really important, because families over the period had both older and younger children involved in this learning. They already knew lots about mushrooms. They knew how to contribute, so the kindergarten had created this historical community knowledge that all could share in, and it gave many of the children a solid base from which to explore the topic. Teachers have learnt it takes time. Don't rush things and put your perceptions onto the children. Listen to the children. By slowing things down, you stop missing vital conversations. The program has been changed to allow this. A successful program isn't based around routines, it is based on children making free choices. That is a huge part of what we do, and it makes the program work, allowing children time, space, and resources to be creative, to think, and to develop and document their ideas using visual arts.

\section{Autumn 2014}

When the mushrooms turned up again, the teachers thought they knew how to extend the interest, what direction it could possibly take. They applied the principles they'd learnt. They didn't rush it. These children were very confident. They came with a huge amount of prior knowledge. An example of this was Felix, who was now almost 5. His older sister had been through the kindergarten, and so Felix had been working with mushrooms since he was 2 years old and he had seen all this documentation occurring. He knew the safety aspects of it; he was the expert in mushrooms.

Teachers had a different starting point to where they'd started three years prior. They joined the children on the mushroom hunts. Teachers didn't rush things. We collected mushrooms, we brought them inside to draw, just like we'd done previously, and we waited. Then one day when on a mushroom hunt, Felix had a chat with the head teacher. During this discussion he asked this question: "Do you know that fairies live under mushrooms?"

From that one question a conversation flourished. The children discussed these questions: Are fairies real? Is it imaginary? Is it reality? Does it matter? They went to a table and started drawing and creating their knowledge about fairies. Children had to decide between reality and imagination. Some children could make that decision. One child said, "If you believe, they're real. If you don't believe, they're not real." While they were drawing and creating, the children continued to raise and discuss questions like, Are fairies magic? Are they nonmagical? What is magic? Are fairies boys? Are fairies girls? The discussions and drawing were providing opportunities for children to build up a theory base around what they knew of fairies. They used their knowledge about the mushrooms to deepen their understanding about fairies, but mushrooms and 
fairies were completely different subject matters. One involved a scientific understanding of the natural world, and another was completely imaginary, yet the two topics were able to run side by side.

The interest flourished and grew. Children started to create fairy houses and gardens (see Figure 8). In Figure 9 there is an example of a child who has drawn the house and then is using clay to create it. Clay was always available in the environment, so children were able to use the knowledge and skills they had built with clay work to make clay houses. One girl came with a knowledge about fairy gardens. Her mother had been building them with her at home, so she was able to link her learning from home and share it with her friends at kindergarten. Moss she found in the garden became her fairies' pillow. The children decided to write to the fairies (Figure 10) and request that they visit. Alongside teachers, they emailed them and used surface post. This happened over a period of two weeks. There was a lot of documentation through art happening and children were practicing literacy and early writing skills. The fairies wrote back saying they were going to come and visit.

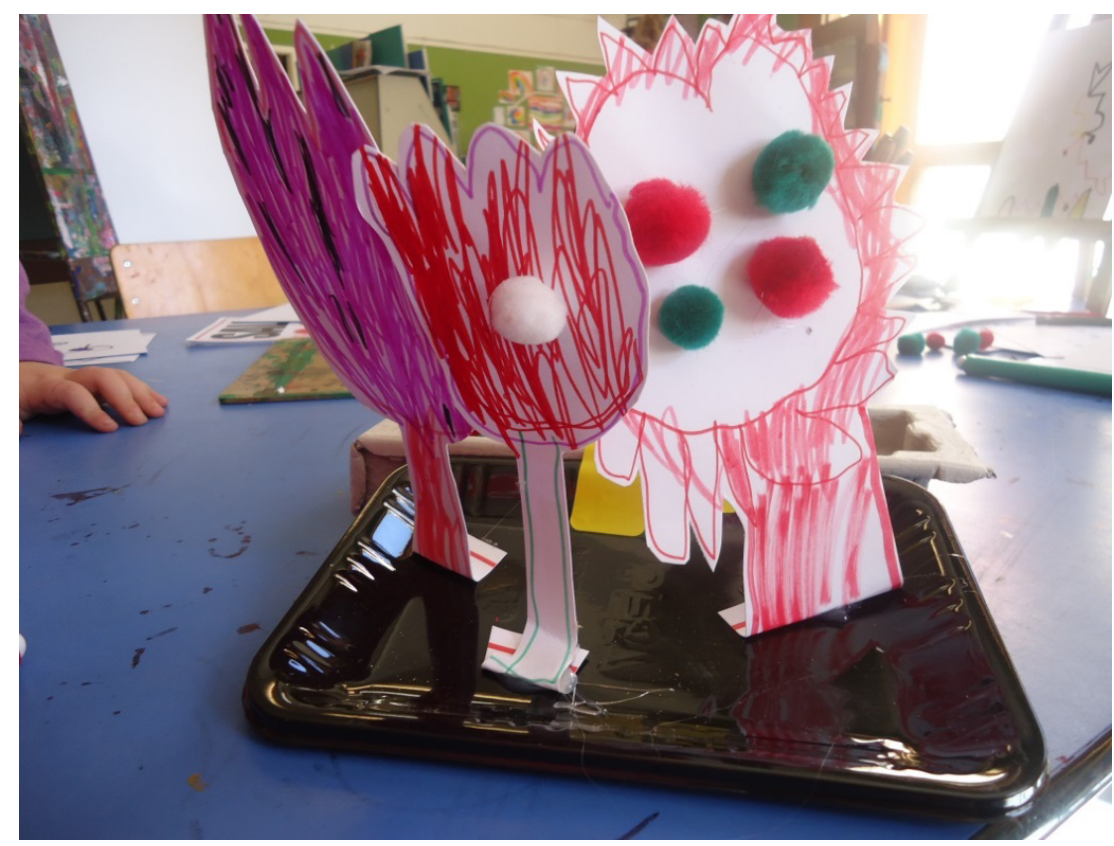

Figure 8. One of the many fairy gardens children created.

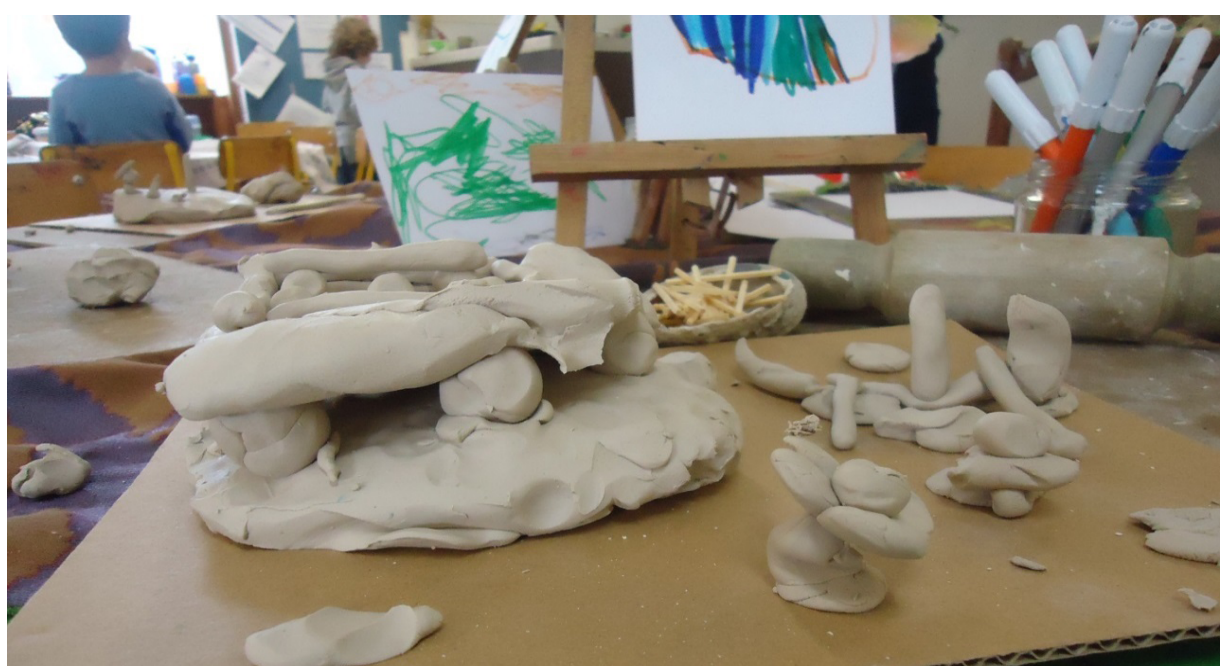

Figure 9. One of the clay fairy houses with the predrawn plan on the easel in the background. 


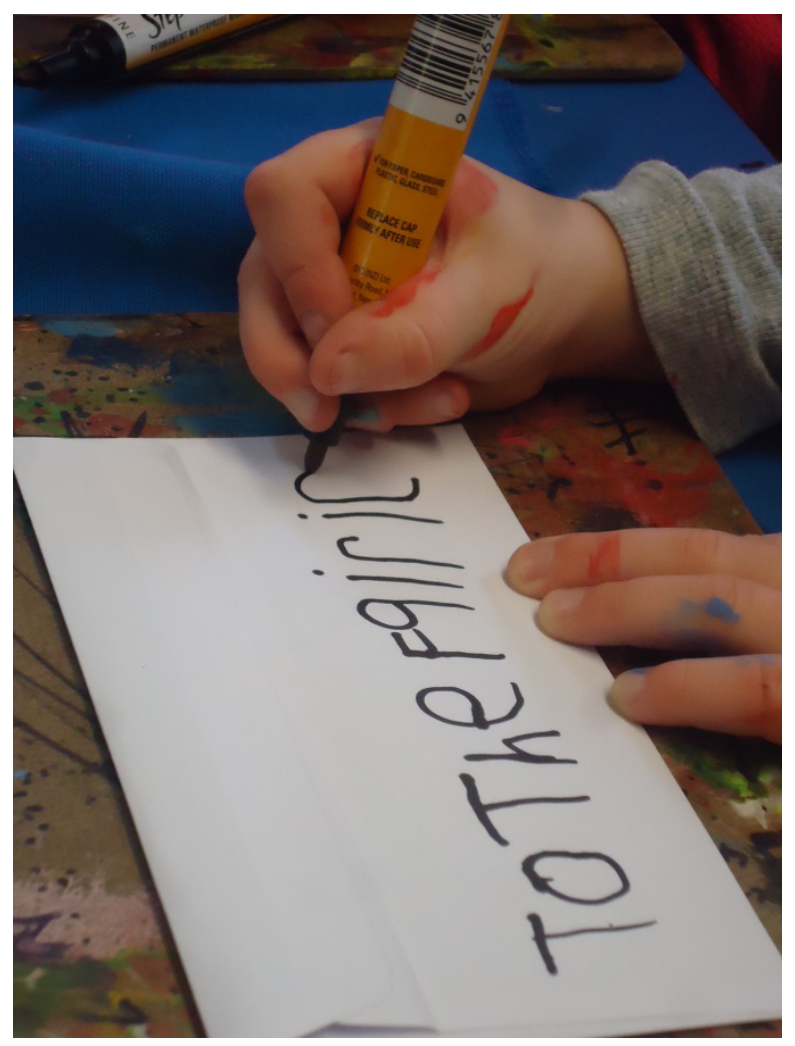

Figure 10. Addressing one of the letters to the fairies.

\section{Preparing to Welcome the Fairies}

The children's imaginations went into overdrive. Each child created their own fairy, which they named, and many gave them magical powers. They included details in their drawings that they'd worked out in discussions. Some children wanted wings on their fairies. Some of them had to have sparkly glitter on them because they were magical. Some children had to make them boy fairies, because they were quite insistent that their fairy was a boy, so all those conversations that we'd had with the children were starting to come through in their pictures. The children's art was displayed (Figure 11) so that it welcomed the fairies when they arrived at our kindergarten. The fairies moved into our tree in our garden on the day of the fairy party. When the children arrived, it was very apparent that fairies had been there because there was fairy dust everywhere. A door had appeared in our tree, and there were mushrooms that hadn't been there before. The children could tell from these cues that the fairies were at kindergarten. But no one could actually see the fairies. The children did not question the fact that they couldn't actually see the fairies. They didn't require a physical manifestation of a fairy. In their minds, the fairies were there. It showed us the value of those conversations around fairies. 


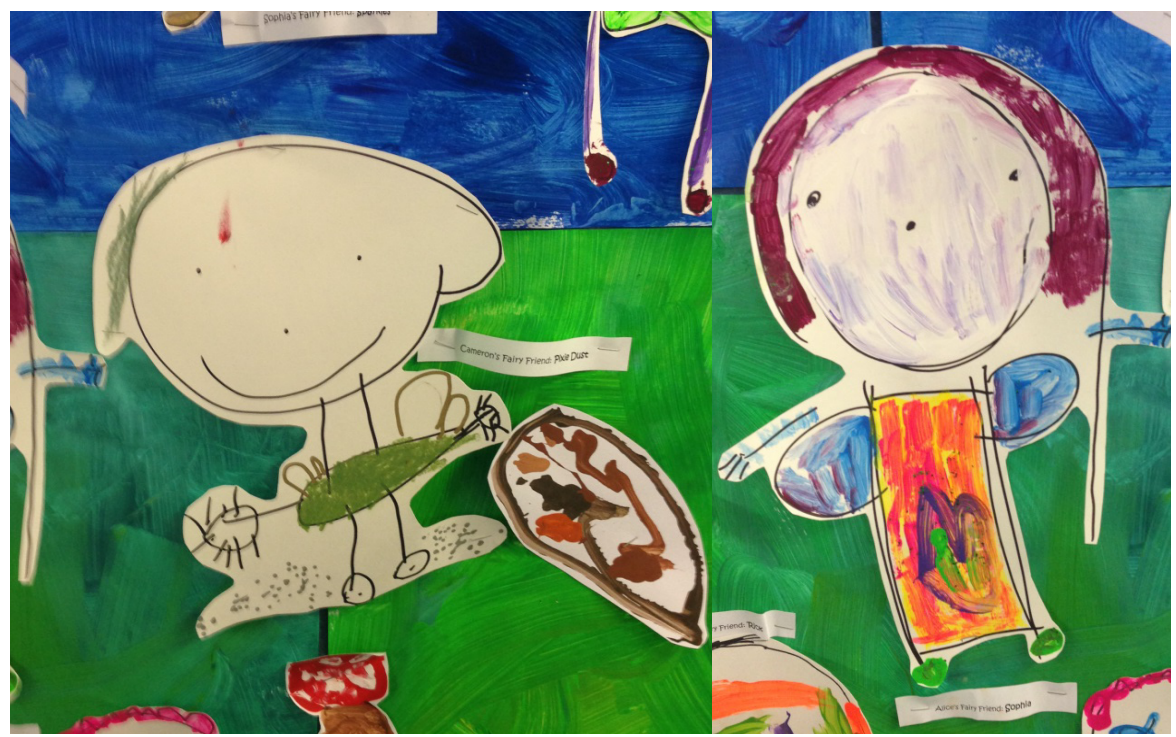

Figure 11. Children drew their idea of a fairy complete with magic powers.

The kindergarten had a party and a community feast to celebrate the fairies' arrival. This was like a celebration of three years' work. All that accumulated knowledge that we had developed as a community was celebrated. Families contributed food and children were dressed up, as were the teachers. The families came and joined in the celebration, too. It was such a different evolution from our first foray into making discoveries about our immediate natural world. It was not less valuable because it was imaginary; it was just a different outlet for children to make sense of their world, and to express themselves.

\section{Interpretations and Conclusions}

Using rhizomatic thinking as we consider the fungi to fairies narrative enables us to see a number of plateaus where children, teachers, parents, and families were being, becoming, encountering, (re)connecting and... and... and.... Children came in and out of experiences and interests, being/becoming artists, communicators, learners, experts, and decision makers. The provocation of the mushrooms reappearing over time brought some of the children back to a previously visited plateau where they could revisit their thinking through the retained documentation. They were able to intensify their ideas and bring the experience of other activities to the plateau. Families and siblings, both older and younger, shared their experiences and participated in their thinking. Some families developed connecting/adjacent rhizomes as they played with the ideas of their children in the home setting, bringing new thinking and experiences to the learning.

The teachers were involved in a rhizomatic way, being/becoming learners, listeners, artists, communicators, and experts. They let go of the linear thinking of a beginning and an end. The experiences weren't about being "taught" the topic of mushrooms and learning/knowing a finite number of facts, but exploring/investigating an infinite number of ideas and possibilities. In the background was another plateau where children and teachers were being/becoming the curriculum. The nonprescriptive nature of Te Whāriki supports teachers to explore/lead/follow/discover and (re)invent teaching strategies to support a multiplicity of outcomes. When provocation from a child in the form of a question produced a line of flight, the curriculum/children/teachers/families were willing and able to investigate and explore the new plateau. By removing the previous linear aspects of the daily program (set routines and adult control of resources), the whole learning community gained greater depth and involvement in learning.

A strong visual arts program, another rhizome where children were building intensity, enabled the children to see themselves as artists with the skills to communicate, explore, investigate, and develop their ideas, and supported the exploration of their working theories. Children were able to use art to document their learning and ideas whether or not their creations 
were representational because teachers took the time to learn and inquire alongside the children. Teachers participated in conversations with children as they recorded their ideas or created an interpretation of their thinking, not rushing the process. The documentation through the visual arts provided a link for the parents and families and continuity of learning across environments.

This article has focused on the reoccurrence of a natural phenomenon at the kindergarten and the experiences relating to it. There were a myriad of other learning experiences happening throughout this time as children and teachers developed interests within a culture of inquiry and documented these interests using visual arts. These experiences formed other rhizomes and some plateaus. All this learning is happening in/within/alongside/between the spaces provided by the curriculum, the teachers, and the environment. The mushrooms will come again and... and... and...

\section{References}

Amorim, A. C., \& Ryan, C. (2005). Deleuze, action research, and rhizomatic growth. Educational Action Research, 13(4), 581-593. doi: 10.1080/09650790500200306

Brooks, M. (2009). Drawing, visualisation, and young children's exploration of "big ideas." International Journal of Science Education, 31(3), 319-341. doi: 10.1080/09500690802595771

Chapman, J., \& Kitanov, V., III. (1986). The terrible wild grey hairy thing. Sydney, Australia: Scholastic Australia.

Duncan, J., \& Eaton, S. (2013). A rhizomatic experiment with learning stories. Global Studies of Childhood, 3(3), 318-327. doi: $10.2304 /$ gsch.2013.3.3.318

Griebling, S. (2011). Discoveries from a Reggio-inspired classroom: Meeting developmental needs through the visual arts. Art Education, March, 6-11.

Hargraves, V. (2014). Children's theorising about their world: The practitioner's role. Australian Journal of Early Childhood, $39(1), 30-37$.

Hedges, H., \& Jones, S. (2012). Children's working theories: The neglected sibling of Te Whāriki's learning outcomes. Early Childhood Folio, 16(1), 34-39.

MacDonald, A. (2013). Using children's representations to investigate meaning-making in mathematics. Australian Journal of Early Childhood, 38(2),65-73.

New Zealand Ministry of Education. (1996). Te whāriki: He whāriki mātauranga mō ngā mokopuna o Aotearoa : Early childhood curriculum. Wellington, New Zealand: Learning Media.

New Zealand Ministry of Education. (2009). Kei tua o te pae assessment for learning: Early childhood exemplars, the arts, $n g \bar{a}$ toi. Wellington, New Zealand: Learning Media.

Osgood, J., Albon, D., Allen, K., \& Hollingworth, S. (2013). "Hard to reach" or nomadic resistance? Families "choosing" not to participate in early childhood services. Global Studies of Childhood, 3(3), 208-220. doi: 10.2304/gsch.2013.3.3.208

Pohio, L. (2009). Reggio Emilia pedagogy in early childhood education: How can this approach enhance visual arts experiences in New Zealand? He Kupu/The Word, 2(2), 10-18.

Sellers, M. (2013). Young children becoming curriculum: Deleuze, Te Whāriki, and curricular understandings. London, 
England: Routledge.

Stott, J. (2011). Teaching visual arts: Putting theory into practice. He Kupu/The Word, 2(4), 34-40.

Terreni, L. (2010). A history of visual art education in early childhood in New Zealand: Looking backwards to go forwards. International Art in Early Childhood Research Journal, 2(1),1-11. Retrieved from: http://artinearlychildhood.org/ artec/images/article/ARTEC_2010_Research_Journal_1_Article_2.pdf 